\title{
El receptor soluble de insulina y el síndrome metabólico
}

\author{
Marcia Hiriart-Urdanivia, ${ }^{*}$ Carmen Sánchez-Soto, Myrian Velasco, Jean Sabido-Barrera y \\ Rosa Isela Ortiz-Huidobro \\ Universidad Nacional Autónoma de México, Instituto de Fisiología Celular, Departamento de Neurociencia Cognitiva, Ciudad de México, México
}

\begin{abstract}
Resumen
El síndrome metabólico es un conjunto de signos que aumentan la probabilidad de desarrollar diabetes mellitus tipo 2, enfermedades cardiovasculares y algunos tipos de cáncer. La acción de la insulina depende de su unión a los receptores en la membrana de sus células diana. Para responder a la pregunta de si la insulina en la sangre podría viajar unida a proteínas y si en presencia de hiperinsulinemia podría generarse un receptor soluble de insulina, utilizamos ratas wistar (no tienen predisposición a la obesidad ni a la diabetes), adultas jóvenes, a cuya agua de consumo se adicionó 20 \% de azúcar y a las que se les administró dieta estándar ad libitum, durante dos y seis meses; fueron comparadas con ratas control que tuvieron las mismas condiciones, pero con agua corriente para consumo. A los dos meses, las ratas desarrollaron obesidad central, hipertensión moderada, triglicéridos altos, hiperinsulinemia, intolerancia a la glucosa y resistencia a la insulina, es decir, síndrome metabólico. Se realizó electroforesis de las proteínas del plasma de las ratas, seguida de Western Blot para insulina y para la porción externa del receptor de insulina. Las bandas correspondientes a la insulina y la parte externa del receptor estaban al mismo nivel de peso molecular, 25 veces mayor que el de la insulina libre. Demostramos que la insulina, tanto en animales testigo como en aquellos con hiperinsulinemia, viaja unida a la porción externa del receptor (ectodominio), al cual denominamos receptor soluble de insulina, que se libera en mayor cantidad en respuesta al incremento en la insulina plasmática; en las ratas con síndrome metabólico e hiperinsulinemia, los niveles en plasma son mucho mayores que en los controles. El incremento del receptor soluble de insulina en sangre podría ser un dato temprano de síndrome metabólico.
\end{abstract}

PALABRAS CLAVE: Receptor soluble de insulina. Hiperinsulinemia. Resistencia a la insulina.

\section{Abstract}

The metabolic syndrome describes a group of signs that increase the likelihood for developing type 2 diabetes mellitus, cardiovascular diseases and some types of cancer. The action of insulin depends on its binding to membrane receptors on its target cells. We wonder if blood insulin could travel bound to proteins and if, in the presence of hyperinsulinemia, a soluble insulin receptor might be generated. We used young adult Wistar rats (which have no predisposition to obesity or diabetes), whose drinking water was added $20 \%$ of sugar and that were fed a standard diet ad libitum for two and six months. They were compared with control rats under the same conditions, but that had running water for consumption. At two months, the rats developed central obesity, moderate hypertension, high triglyceride levels, hyperinsulinemia, glucose intolerance and insulin resistance, i.e. metabolic syndrome. Electrophoresis of the rats' plasma proteins was performed, followed by Western Blot (WB) for insulin and for the outer portion of the insulin receptor. The bands corresponding to insulin and to the receptor external part were at the same molecular weight level, 25-fold higher than that of free insulin. We demonstrated that insulin, both in control animals and in those with hyperinsulinemia, travels bound to the receptor outer portion (ectodomain), which we

Correspondencia:

*Marcia Hiriart-Urdanivia

E-mail: mhiriart@ifc.unam.mx
Fecha de recepción: 25-03-2018

Fecha de aceptación: 27-03-2019

DOI: $10.24875 / G M M .19005185$
Gac Med Mex. 2019;155:541-545

Disponible en PubMed

www.gacetamedicademexico.com 
called soluble insulin receptor, and that is released al higher amounts in response to plasma insulin increase; in rats with metabolic syndrome and hyperinsulinemia, plasma levels are much higher than in controls. Soluble insulin receptor increase in blood might be an early sign of metabolic syndrome.

KEY WORDS: Soluble insulin receptor. Hyperinsulinemia. Insulin resistance.

\section{El problema de salud}

El siglo XXI se inició con una epidemia de sobrepeso y obesidad. El número de personas con obesidad en el mundo ha aumentado al doble de 1980 a la fecha. Aproximadamente $40 \%$ de la población mundial adulta (1900 millones) tiene sobrepeso y $13 \%$ de ella, obesidad. En México, los datos no son mejores: según la Encuesta Nacional de Salud y Nutrición de 2016, siete de cada 10 adultos tienen sobrepeso u obesidad. Para aumentar la alarma, tres de cada 10 niños en edad escolar y cuatro de cada 10 adolescentes también tienen exceso de peso, con los problemas que conlleva. Es necesario entender cómo se desarrollan los signos del síndrome metabólico y progresan hacia diabetes mellitus tipo 2 (DM2). Aun cuando en la literatura hay numerosos artículos sobre síndrome metabólico y DM2 que se enfocan a la clínica, hay conceptos básicos de fisiología de la insulina que no se comprenden.

\section{Síndrome metabólico y DM2}

El síndrome metabólico es un conjunto de signos que aumenta la probabilidad de desarrollar DM2, enfermedades cardiovasculares y algunos tipos de cáncer. Se considera síndrome metabólico la manifestación de tres de los siguientes signos: obesidad central, hipertensión, dislipidemia, hiperinsulinemia, alteración en la glucosa de ayuno y resistencia a la insulina. Contrarrestarlos puede prevenir el desarrollo de patologías más severas, como la DM2., ${ }^{1,2}$

La DM2 es una enfermedad que se manifiesta por hiperglucemia, secundaria a un agotamiento de las células beta, las únicas en el organismo que producen y secretan insulina. Se dice que las células beta se agotan cuando no puede mantener la homeostasis de la glucosa (glucosa en ayunas < $125 \mathrm{mg} / \mathrm{dL}$ ); es una enfermedad multifactorial, poligénica, que depende de factores internos como la microbiota y externos como la dieta, la exposición a contaminantes ambientales, etcétera. En México, la genética de la población mestiza indica que tiene mayor probabilidad de desarrollar DM2.
Con frecuencia, antes de que se produzca hiperglucemia hay resistencia a la insulina (hay producción de insulina pero el organismo no responde a ella), además de una estimulación excesiva de las células beta, lo cual las lleva al agotamiento. Esto explica que el síndrome metabólico preceda a la DM2.

Durante el desarrollo, la pubertad y el embarazo hay estadios temporales de resistencia a la insulina fisiológica, que se asocian con periodos de hiperinsulinemia e hiperglucemia.

\section{Fisiología de la insulina y su receptor}

La insulina es una hormona peptídica, secretada únicamente por las células beta pancreáticas como un hexámero estabilizado por cinc, el cual se disocia y transporta a la forma activa de insulina, la cual está formada por las subunidades A y B, entre las cuales hay tres puentes, dos de disulfuro y uno intracatenario en la subunidad $A$.

El estímulo más importante en la secreción de la insulina es la alfa d-glucosa, pero algunos aminoácidos y ácidos grasos también están involucrados. Al comer, los nutrientes se absorben y llegan al páncreas mediante el sistema porta. Cuando aumenta la concentración de glucosa, aumenta la secreción de insulina. La célula beta convierte las señales químicas en eléctricas y se secretan los gránulos de insulina al aumentar la concentración de calcio intracelular. ${ }^{3}$ En general se acepta que la hormona viaja libre en la sangre.

Todas las células del organismo tienen receptores a insulina, pero son más abundantes y su acción es más clara en el hígado, la grasa y los músculos esqueléticos. Los receptores de insulina pertenecen a la familia de receptores con actividad de cinasa de tirosina y son heterodímeros formados por dos subunidades, alfa y beta. La subunidad alfa une la insulina y la beta tiene el dominio de la cinasa. Las subunidades alfa y beta están conectadas por un puente disulfuro y las subunidades alfa presentan de dos a cuatro puentes. Se ha observado que cada subunidad puede unir una molécula de insulina con alta afinidad y otra con baja afinidad. ${ }^{4}$ 
La unión de la insulina al receptor inicia la señal y continúa con un cambio conformacional que produce transfosforilación de las subunidades beta, lo cual inicia una cadena proteína a proteína de fosforilaciones intracelulares, que lleva a que Akt2 promueva el transporte de Glut4 a la membrana y al aumento en la entrada de glucosa, la síntesis de glucógeno, triglicéridos y proteínas, según el tejido que se trate, y también a la activación de la cinasa de proteínas activada por mitógenos que media la regulación de la expresión génica. ${ }^{4}$

\section{Desarrollo de un modelo animal de síndrome metabólico}

Escogimos a las ratas wistar porque no tienen tendencia a la obesidad ni a desarrollar diabetes, adultos jóvenes de dos meses y medio; fueron alimentadas con dieta normal y agua adicionada con $20 \%$ de azúcar. Las comparamos con sus controles dos y seis meses después de iniciado el tratamiento. Desde la comparación a los dos meses se identificó que las ratas macho habían desarrollado obesidad central, hipertensión moderada, triglicéridos altos, intolerancia a la glucosa y resistencia a la insulina, es decir, síndrome metabólico. ${ }^{2,5}$ Observamos que el desarrollo del síndrome metabólico difirió notablemente entre los sexos: a los seis meses, las ratas macho del grupo experimental presentaban un síndrome metabólico más acentuado; al principio, las hembras fueron más intolerantes a la glucosa y tardaron más en desarrollar el síndrome.

Hemos observado que en el síndrome metabólico el hígado se vuelve graso, la grasa misma, cuyas células crecen mucho, secretan muchas hormonas y las invaden glóbulos blancos; el organismo se siente inflamado. Las células beta secretan una gran cantidad de insulina llevando a hiperinsulinemia, condición que de prolongarse ocasiona que las células se agoten y se desarrolle diabetes mellitus tipo 2. A los seis meses de iniciado el experimento, las ratas estaban más obesas y las células beta empezaron a descomponerse y a no secretar la suficiente insulina como para mantener la glucosa en la sangre en niveles normales, especialmente en los machos.

\section{El transporte de la insulina en el plasma}

Por tratarse de un péptido, se considera que la insulina viaja libre en la sangre hasta sus órganos diana. Sin embargo, recientemente se ha demostrado
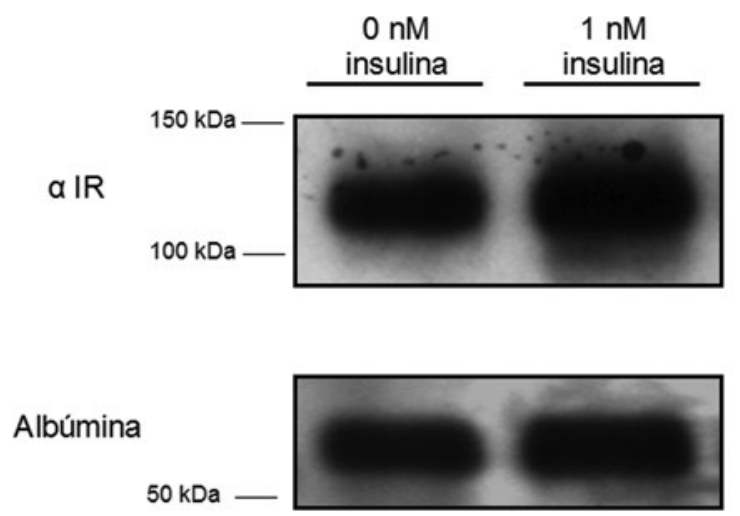

Figura 1. Representación de la liberación del receptor soluble de insulina de adipocitos de rata. Inmunoblot para la cadena alfa del receptor de insulina en el medio de cultivo de adipocitos aislados. Las células $\left(2 \times 10^{6}\right.$ células) fueron tratadas con $1 \mathrm{nM}$ de insulina durante 30 minutos, posteriormente se obtuvo el medio de cultivo celular, el cual fue concentrado por filtración para su posterior análisis. El grupo control fue estimulado con $0.001 \%$ de dimetilsulfóxido y como control de carga se realizó Inmunoblot para albúmina.

que solo una pequeña fracción de la insulina transita libre en la sangre; el resto de la hormona viaja unida al ectodominio del receptor de insulina (receptor soluble de insulina).

Analizamos in vitro la liberación de la subunidad alfa del receptor en hepatocitos de rata, dado que son ricos en receptor de insulina. Al aplicar concentraciones crecientes de insulina resultó claro que la liberación aumenta significativamente cuando la concentración de insulina en el medio extracelular se incrementa, llegando a un máximo en $1 \mathrm{nM}$ de insulina. Esta liberación se previene si en el medio de incubación de los hepatocitos se incluye un inhibidor de proteasas. ${ }^{3}$ La insulina se puede unir a la albúmina, pero con menor afinidad. Desconocemos si los complejos proteína a proteína se disocian, permitiendo a la insulina interactuar con los receptores de insulina de la membrana.

\section{Mecanismos de resistencia a la hiperinsulinemia}

La hiperinsulinemia es incompatible con la vida, por lo que los mamíferos desarrollaron mecanismos para contrarrestarla. A corto plazo, el receptor soluble de insulina puede neutralizar la insulina secretada en exceso; a largo plazo, los tejidos pueden volverse resistentes a la hormona, además de continuar neutralizándola mediante el receptor soluble de insulina.

La cantidad de receptor fue mayor en las ratas con síndrome metabólico que en las rata control, lo cual 


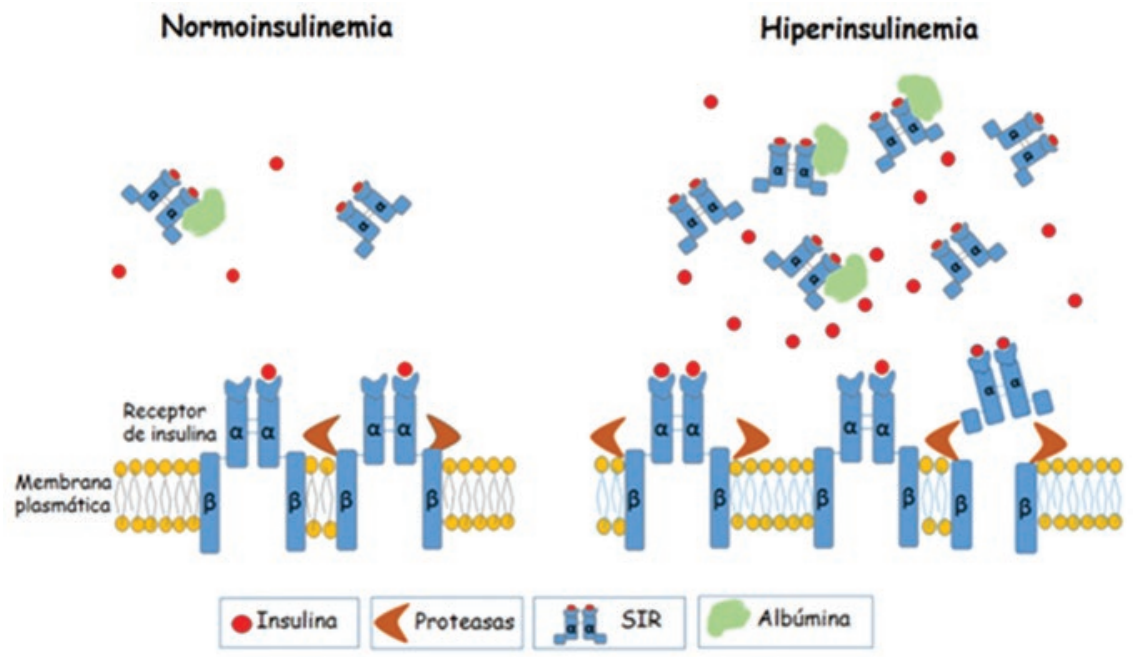

Figura 2. Receptor de insulina en hepatocitos controles y tratados con insulina $1 \mathrm{nM}$. En los hepatocitos control se identificó receptor de insulina en la membrana; al aumentar la insulina se incrementó la actividad de proteasas, como sucede con la hiperinsulinemia, en la que hay actividad de las proteasas y se despega más ectodominio del receptor de insulina soluble.

probablemente está relacionado con la hiperinsulinemia. La incubación de los hepatocitos con insulina y un inhibidor de proteasas disminuye la cantidad de receptor soluble de insulina liberado al medio. Recientemente, hemos comprobado la presencia de este mismo fenómeno en adipocitos de rata al incubarlos con insulina a una concentración de 1nM: hubo incremento en la liberación del receptor soluble en comparación con las ratas control (Figura 1).

\section{Receptor soluble de insulina en la diabetes y síndrome metabólico}

Un grupo de investigadores mostró que en pacientes con diabetes se podía detectar una forma soluble de receptor de insulina, ${ }^{6}$ que identificó como un problema de salud en respuesta a la hiperglucemia y no como una condición fisiológica. Una parte de ese grupo siguió trabajando en el tema y describió que este evento podría ser parte de la resistencia a la insulina. Demostraron una correlación positiva entre el receptor soluble de insulina y la concentración extracelular de glucosa y la hemoglobina glucosilada A1c. ${ }^{?}$

No solo el ectodominio del receptor de insulina se ha encontrado en el plasma, sino también en leptina, factor de necrosis tumoral alfa, etcétera. Este fenómeno se conoce como shedding (desprendimiento de la membrana) y es llevado a cabo por proteasas. En el caso del receptor soluble de insulina en células tumorales de hígado Hep2, los autores sugieren que no se trata de una metaloproteasa MMP, ni de una enzima tipo ADAM porque no las detectan en sus ensayos. Los autores proponen que a mayor glucosilación del receptor, mayor facilidad para ser atacado por las proteasas. Asimismo, en ese modelo se requiere glucosamina unida a $\mathrm{O}-\mathrm{N}$-acetil modificada y una proteasa dependiente de calcio para que se lleve a cabo el desprendimiento del receptor. ${ }^{7}$

Nuestro grupo ha encontrado que las ratas con síndrome metabólico tienen mucho más receptor soluble en plasma, lo que puede correlacionarse con el aumento de la insulina. Asimismo, hemos encontrado que los niveles plasmáticos de receptor soluble de insulina están más aumentados en las ratas con mayor hiperinsulinemia (Figura 2). En las hembras, la insulina no se incrementa tanto a los seis meses de estar ingiriendo el agua con azúcar y esto se correlaciona también con un nivel menor de receptor soluble de insulina circulante.

\section{Perspectivas}

Los resultados de la unión de la insulina circulante con el receptor soluble de insulina son de interés clínico tanto para el diagnóstico como para el seguimiento de los niveles en sangre. Por otro lado, el tratamiento con alguna enzima específica que inhiba la proteólisis del receptor podría aumentar el receptor soluble de insulina y la cantidad de insulina libre en el plasma, la hormona activa biológicamente. El estudio de la unión plasmática de insulina a proteínas podría llevar a encontrar alguna forma de limitar la resistencia a la insulina. 


\section{Referencias}

1. Hiriart M, Velasco M, Larqué $C$, Díaz-García $C M$. Metabolic syndrome and ionic channels in pancreatic beta cells. Vitam Horm. 2014:95:87-114.

2. Velasco M, Larqué C, Gutiérrez-Reyes G, Arredondo R, Sánchez-Soto $\mathrm{C}$, Hiriart M. Metabolic syndrome induces changes in KATP-channels and calcium currents in pancreatic $\beta$-cells. Islets. 2012;4:302-311.

3. Hiriart M, Sánchez-Soto C, Díaz-García CM, Castanares DT, Avitia M, Velasco M, et al. Hyperinsulinemia is associated with increased soluble insulin receptors release from hepatocytes. Front Endocrinol (Lausanne). 2014;5:95
4. Tatulian SA. Structural dynamics of insulin receptor and transmembrane signaling. Biochemistry. 2015;54:5523-5532.

5. Larque C, Velasco M, Navarro-Tableros V, Duhne M, Aguirre J, Gutiérrez-Reyes $\mathrm{G}$, et al. Early endocrine and molecular changes in metabolic syndrome models. IUBMB Life. 2011;63:831-839.

6. Soluble Insulin Receptor Study Group. Soluble insulin receptor ectodomain is elevated in the plasma of patients with diabetes. Diabetes. 2007:56:2028-2035.

7. Yuasa T, Amo K, Ishikura S, Nagaya H, Uchiyama K, Hashida S, et al. Development of in vitro model of insulin receptor cleavage induced by high glucose in HepG2 cells. Biochem Biophys Res Commun. 2014; $445: 236-243$. 